\title{
Envolvimento Paterno aos Três Meses de Vida do Bebê ${ }^{1}$
}

\author{
Cesar Augusto Piccinini \\ Milena da Rosa Silva \\ Tonantzin Ribeiro Gonçalves \\ Rita de Cássia Sobreira Lopes \\ Universidade Federal do Rio Grande do Sul \\ Jonathan Tudge \\ University of North Carolina at Greensboro
}

\begin{abstract}
RESUMO - O presente estudo investigou o envolvimento paterno aos três meses de vida do bebê. Foram entrevistados 38 pais primíparos, com idades entre 20 e 40 anos. Realizou-se uma análise de conteúdo baseada nas dimensões do conceito de envolvimento paterno: interação, acessibilidade e responsabilidade. Os pais revelaram envolverem-se nas atividades de cuidado, embora nem sempre de maneira rotineira. Também relataram preocupações e envolvimento nas decisões relativas aos cuidados, educação e saúde do bebê. Contudo, consideravam que sua participação estava aquém da ideal em função das restrições impostas pelo trabalho. Os resultados apontam para um aumento no envolvimento paterno nos primeiros meses do bebê e para a necessidade de apoio aos pais neste momento de transição familiar.
\end{abstract}

Palavras-chave: envolvimento paterno, relação pai-bebê; paternidade.

\section{Fathers' Involvement During the Baby's Third Month}

\begin{abstract}
This study investigated the involvement of fathers when their baby was three months old. Participants included 38 primiparous fathers with ages from 20 to 40 years. The fathers' interviews were content analyzed, based on three dimensions of father involvement: interaction, accessibility and responsibility. Fathers reported their involvement in many care activities, although not always routinely. They also mentioned worries and a much involvement in decisions related to care, education and baby's health. However, fathers considered their participation less than desired due to work-related time restrictions. These results indicated an increase in father involvement during the baby's third month and the need for emotional support for the fathers during this family transition.
\end{abstract}

Keywords: father involvement, father-baby relationship; fatherhood.

O nascimento do primeiro filho traz diversas mudanças na vida do casal. De acordo com Cramer e Palacio-Espasa (1993), a chegada de um filho, principalmente do primeiro, constitui uma fase nova do desenvolvimento e, portanto, traz a necessidade de uma série de adaptações. Neste momento, é imposta à mãe e ao pai uma tarefa considerável de redistribuição de seus investimentos emocionais, impulsionada pela inclusão do bebê em sua organização psíquica. Assim, durante o primeiro trimestre de vida do bebê, a família precisa reorganizar-se emocionalmente, bem como a sua rotina, para atender às exigências do bebê e se adaptar aos novos papéis com que se defrontam. Em especial para o pai, os primeiros meses após o nascimento parecem ser vivenciados de maneira distinta da mãe, visto que, durante a gestação, o vínculo pai-bebê era mediado por ela (May, 1982). Neste sentido, já durante a gravidez pode ser verificado um expressivo envolvimento dos pais com seus filhos, tanto em termos emocionais quanto comportamentais, o que facilita a constituição

1 Agradecemos ao CNPq, a Spencer Foundation - EUA pelo apoio financeiro concedido para realização do presente estudo, e a Fulbright Commission por apoiar o quinto autor durante o tempo de trabalho neste artigo. Endereço para correspondência: piccinini@portoweb.com.br

2 Endereço para correspondência: Instituto de Psicologia, Universidade Federal do Rio Grande do Sul, Rua Ramiro Barcellos, 2600, Porto Alegre, RS. CEP 90350-003.E-mail: piccinini@portoweb.com.br da relação pai-bebê (Piccinini, Silva, Gonçalves, Lopes \& Tudge, 2004). De qualquer modo, é com a presença física do bebê, a partir do nascimento, que o pai pode desenvolver uma relação direta com ele.

Alguns autores afirmam que os primeiros momentos de interação entre pai e bebê podem provocar intensos sentimentos nos pais, como vaidade pelo filho, comprovação da potência reprodutiva e auto-estima elevada (Lebovici, 1987; Ramires, 1997). Brazelton (1988) ressalta que os pais podem experimentar certa alternância de sentimentos que iria desde o êxtase até uma grande preocupação em função das novas responsabilidades. Ao mesmo tempo, a relação com o bebê faria com que os pais revivessem suas experiências infantis com seus primeiros objetos (Ramires, 1997). Em função da intensidade emocional própria a este período, alguns pais podem vivenciar conflitos relacionados à parentalidade $\mathrm{e}$ sentimentos de ciúmes e exclusão da díade mãe-bebê. Além disso, conforme Brazelton (1988), a ansiedade e o sentimento de inexperiência dos pais também poderiam dificultar a aproximação com o filho.

Considerando as vivências concretas e emocionais do pai e da mãe, Houzel (2004) propôs três eixos de compreensão da parentalidade: o exercício, a experiência e a prática da parentalidade. Segundo o autor, o exercício da parentalidade diz respeito aos direitos e deveres dos genitores em uma 
sociedade. Já a dimensão da experiência abarca os aspectos subjetivos da transição para a parentalidade. Por fim, a prática considera as interações comportamentais e afetivas em cuidados e brincadeiras no dia-a-dia com o filho. No presente estudo, será enfocado o eixo da prática da parentalidade, através do conceito de envolvimento paterno, conforme descrito por Lamb, Pleck, Charnov e Levine (1985).

Tradicionalmente, os papéis atribuídos a homens e mulheres no que se refere à prática da parentalidade costumavam assumir diferentes aspectos, já que a mãe seria a cuidadora primária e o pai, responsável pelo suprimento material à família (Ramires, 1997). No entanto, ainda na década de 1980, Brazelton (1988) já destacava a importância da participação mais igualitária do pai na criação dos filhos, não somente no apoio à mãe, mas também colaborando com os cuidados e as decisões sobre a criança. A literatura sobre pais norte-americanos concorda que esses vêm modificando seu envolvimento na vida familiar, assumindo outras tarefas com os filhos (Cabrera, Tamis-LeMonda, Bradley, Hofferth \& Lamb, 2000). No entanto, pouco ainda se sabe sobre o envolvimento de pais brasileiros com seus filhos. A figura de um pai distante e incompetente para os cuidados primários não mais corresponde à realidade. A maciça entrada das mulheres no mercado de trabalho e outros fatores sócio-econômicos podem estar determinando uma maior participação do pai nos cuidados com a criança (Bailey, 1994; Cabrera et al., 2000). Neste sentido, em um estudo transcultural comparando as atividades diárias de crianças de três anos, Tudge et al., (2006) encontraram que os pais brasileiros foram mais igualitários do que pais em outros seis países (incluindo pais norte-americanos) engajando-se em brincadeiras e outras interações com seus filhos tanto quanto suas esposas.

Assim, a definição de paternidade ampliou-se a partir desta maior disposição dos pais para atividades anteriormente vistas como típicas da maternidade (Lamb, 1997). Estudos atestaram as habilidades dos pais para a "maternagem" do bebê, demonstrando que a sensibilidade e responsividade paterna não diferem significativamente daquelas apresentadas pelas mães (Belsky, Gilstrap \& Rovine, 1984; Easterbrooks \& Goldberg, 1984). Ao mesmo tempo, autores acreditam que os pais influenciam de forma particular o desenvolvimento dos filhos, distinguindo-se das mães por proporcionar interações mais rítmicas e corporais e por oferecer um apoio menos próximo (Brazelton, 1988; Lebovici, 1987; Roggman, 2004; Tamis-Lemonda, 2004). No estudo de Belsky et al. (1984) enquanto as mães foram mais estimuladoras, responsivas e demonstravam mais afeto do que os pais ao longo dos primeiros nove meses, os pais eram mais engajados em ler e assistir televisão. No entanto, os autores afirmam que as diferenças quantitativas entre pais e mães tendem a diminuir ao longo do desenvolvimento do bebê, apontando que a experiência dos pais com o filho e a redução do tempo das mães com os bebês acarreta um maior envolvimento dos pais e maior facilidade para assumir o papel parental.

Assim, apesar de existirem muitos estudos descritivos sobre comportamentos, características e influências do pai sobre a criança, bem como sobre as diferenças entre mães e pais, Roggman (2004) considera necessárias elaborações teóricas mais consistentes no que diz respeito à paternidade. $\mathrm{O}$ conceito de envolvimento paterno tem sido útil para a compreensão da relação pai-filho. Esse conceito tem sido caracterizado de diferentes maneiras na psicologia e nas ciências sociais, mas uma das definições mais bem aceita e utilizada foi proposta por Lamb et al. (1985). Esses autores delimitaram três componentes para a investigação do comportamento paterno: interação, acessibilidade à criança e responsabilidade. A interação refere-se ao contato direto com o filho, através do cuidado e outras atividades compartilhadas. A acessibilidade diz respeito à presença ou disponibilidade potencial para interagir com a criança. Por fim, a responsabilidade relaciona-se ao papel que o pai desempenha assegurando cuidados e recursos para a criança. Inicialmente, o envolvimento paterno foi operacionalizado de forma quantitativa, medindo-se o número de horas que o pai destinava aos cuidados e outras atividades com a criança. Posteriormente, Parke (1996) apontou a importância dos aspectos relacionados com a qualidade e o conteúdo na análise do envolvimento paterno. Além disso, mudanças na vida familiar como, por exemplo, o grande número de pais que não vivem com seus filhos (por separação do casal ou por geração da criança fora de um relacionamento estável), exigem uma definição mais ampla do conceito (Silva, 2003; Silva \& Piccinini, 2004).

$\mathrm{O}$ envolvimento paterno tem sido relacionado a diversos efeitos positivos sobre o desenvolvimento infantil. Um maior envolvimento dos pais estaria associado com maior competência social e capacidade de regulação emocional das crianças, podendo inclusive moderar efeitos da depressão e não-responsividade materna (Lamb, 1997; Mezulis, Hyde, \& Clark, 2004; Roggman, Boyce, Cook, \& Cook, 2003). Embora o envolvimento paterno venha aumentando nas últimas décadas (Amato \& Gilbreth, 1999), Bailey (1994) afirmou que, ao longo da primeira infância, ele permanece tendo seu foco na interação social e menos em atividades relacionadas aos cuidados. Deste modo, as mudanças relacionadas ao desempenho do papel paterno podem não ter, ainda, uma influência mais direta sobre os filhos, em particular nos seus primeiros meses de vida. Ainda com relação a isso, Rustia e Abott (1993) alertaram que haveria uma defasagem entre esta nova cultura de paternidade e a conduta efetiva de maior participação nas tarefas com os filhos. Assim, o presente estudo teve como objetivo investigar com se dá o envolvimento paterno durante os primeiros três meses de vida do bebê, descrevendo as formas de envolvimento dos pais com seus filhos no que diz respeito às três dimensões do envolvimento paterno propostas por Lamb et al. (1985) a saber: interação, acessibilidade e responsabilidade.

\section{Método}

\section{Participantes}

Participaram deste estudo 38 pais primíparos, com idades entre 20 e 40 anos. A idade média dos participantes era de $29,4$ anos ( $\mathrm{DP}=5,7)$. Todos viviam com a mãe do bebê que também era primípara. Na ocasião das entrevistas, os bebês tinham entre três e quatro meses de idade completos e não apresentavam problemas de saúde. Os pais eram de níveis 
sócio-econômicos variados e residiam na região metropolitana de Porto Alegre. Quanto ao nível de escolaridade, a maioria dos participantes tinha ensino superior (incompleto: 29\%; completo: $21 \%$; pós-graduação: $5,2 \%$ ). Os demais se distribuíam entre ensino fundamental incompleto $(5,2 \%)$ e completo $(8 \%)$, ensino médio incompleto $(2,6 \%)$ e completo $(29 \%)$. Considerando-se o status ocupacional dos pais (Hollingshead, 1975), as profissões variaram entre "baixo status" (31,5\%; profissões classificadas entre 1 e 4 como, por exemplo, pedreiro, auxiliar de padaria e zelador), "status médio" (24\%; profissões classificadas de 5 a 6 , como representante comercial e técnico em química) e "alto status" ( $42 \%$; profissões classificadas de 7 a 9 como, advogado e dentista).

Os pais do presente estudo foram selecionados, com base nos critérios apontados anteriormente, dentre os participantes do projeto intitulado "Estudo Longitudinal de Porto Alegre: Da Gestação à Escola" (Piccinini, Tudge, Lopes, \& Sperb, 1998). Este estudo acompanhou 81 famílias, cujas gestantes eram primíparas, representando várias configurações familiares, diferentes idades, escolaridade e níveis sócio-econômicos. $\mathrm{O}$ contato inicial para participar deste estudo foi feito com as gestantes no terceiro trimestre de gravidez, através de hospitais da rede pública e privada de Porto Alegre, postos de saúde, anúncios em jornais, e por indicação. O projeto recebeu aprovação do Comitê de Ética dos hospitais envolvidos na coleta de dados e da UFRGS. Quarenta pais preencheram os critérios para participar deste estudo, entretanto dois participantes foram excluídos porque as entrevistas não estavam completas.

\section{Procedimentos e Instrumentos}

Os pais foram convidados para participar do estudo ainda durante a gravidez da companheira. Nessa etapa, a gestante era informada a respeito dos objetivos do estudo e respondia a Ficha de contato inicial (GIDEP, 1998a), a qual buscava verificar se a família possuía as características gerais delineadas para composição da amostra. Preenchendo esses critérios, era marcado um encontro na residência dos participantes, quando a mãe e o pai assinavam o Termo de Consentimento Livre e Esclarecido e respondiam a Entrevista sobre dados demográficos da família (GIDEP, 1998b). Com esta entrevista foram obtidas informações adicionais, como idade, escolaridade, estado civil, ocupação, religião e grupo étnico.

Após o recrutamento e entrevistas realizadas na gestação, que não foram utilizadas no presente estudo, as famílias eram novamente contatadas quando o bebê completava o primeiro trimestre de vida. Os casais eram convidados a participar de novas entrevistas e de uma filmagem da interação familiar, o que também era realizado na residência da família. Para o presente estudo, serão utilizados apenas os dados da Entrevista sobre a Experiência da Paternidade e o Desenvolvimento do Bebê no Primeiro Trimestre (GIDEP, 1999), a qual era respondida pelos pais nesta ocasião. Esta entrevista estruturada e semi-aberta procurava examinar, dentre outras questões, as impressões do pai em relação ao filho, seu desenvolvimento e temperamento, seus próprios sentimentos e dificuldades enquanto pai, o dia-a-dia do pai com o bebê, que tarefas assumia nos cuidados com ele, tipos de brincadeiras que fazia e as suas percepções sobre a companheira como mãe. A entrevista demorava aproximadamente uma hora, era gravada e, posteriormente, transcrita. As respostas dos pais a esta entrevista foram examinadas através da análise de conteúdo (Bardin, 1977; Laville \& Dionne, 1999). Com base nesta técnica, as respostas do pai foram recortadas e organizadas em categorias temáticas.

\section{Resultados}

A partir do conteúdo das respostas dos pais à entrevista sobre a paternidade, bem como nos eixos teóricos do envolvimento paterno (Lamb et al., 1985), foram construídas três categorias: Interação com o bebê, Acessibilidade para o bebê, e Responsabilidades e preocupações com o bebê. Estas foram compostas de diversas subcategorias temáticas, propostas pelos autores, as quais serão apresentadas e discutidas a seguir. Algumas categorias e subcategorias foram ilustradas com vinhetas extraídas das entrevistas ${ }^{3}$. Ao final de cada categoria, são apresentadas tabelas com a distribuição das respostas em cada subcategoria.

\section{Interação com o Bebê}

A categoria Interação com o bebê inclui falas dos pais a respeito das atividades, de cuidado ou lazer, que eles realizam com o bebê e compreende sete subcategorias: brincar, cuidar, conversar, passear, demonstrar afeto, distrair, e estimular. Conforme apresentado na Tabela 1, grande parte dos participantes (34) do presente estudo afirmou realizar atividades de cuidado com o bebê. No entanto, em muitos dos relatos os pais não especificaram a atividade realizada com o bebê ou se referiam apenas aos momentos em que ficavam responsáveis por ele, dando-lhe atenção. Como se verá a seguir, em outras partes da entrevista, a maior parte deles acabou detalhando as atividades com o filho. Para seis pais algumas dessas situações ocorriam quando a mãe precisava fazer outras atividades e então eles ficavam com o filho/a: "Eu fiquei com ele [o filho] na cama e ela [mãe] saiu. (...) Ela foi fazer um trabalho" (P4). Três pais ainda afirmaram ter se responsabilizado pelos primeiros cuidados do bebê no período em que a mãe se recuperava do parto: "Logo que ele nasceu, que daí ela tinha feito cesárea, eu assumi tudo" (P10). Pelo menos oito pais relataram realizar todas as tarefas de cuidado com o filho/a, embora isso pudesse acontecer em caráter eventual ou nos finais de semana: "Quando eu estou em casa no fim de semana, ela [mãe] vai fazer atividades e eu procuro ficar um tempo com ela [a filha]" (P25). Enquanto oito pais mencionaram auxiliar a mãe nos cuidados do bebê, outros onze afirmaram que as tarefas eram divididas pelo casal. Com relação a este aspecto, quatro pais relataram disponibilizar-se, por iniciativa própria, para cuidar do bebê

3 A categorização das entrevistas gerou inúmeros outros exemplos de relatos dos pais, que não foram incluídos no presente artigo por falta de espaço. Em função disto, aqui também se buscou editar algumas citações, excluindo partes que não eram fundamentais para o seu entendimento (indicadas pelo uso de reticências entre parênteses) ou acrescentando expressões para facilitá-lo (indicadas entre colchetes). 
e outros três o faziam mediante solicitação da companheira: "Tudo que eu sei fazer, tudo eu ajudo, eu divido as tarefas com ela [mãe]" (P31); "Quando eu estou presente ela [mãe] faz questão que eu também faça essas coisas com ele. Não é uma coisa nem pesada tipo 'Faz tu que eu não vou fazer' e também, não, é renegando assim, deixando o pai de fora. Não. Dentro das possibilidades ela me pede para fazer as coisas" (P35).

As atividades de cuidado do bebê que os pais afirmaram realizar, seja de maneira rotineira ou eventual, foram trocar fraldas, dar banho, pegar no colo, alimentar, preparando e dando ao bebê a mamadeira ou alimentos pastosos, atendê-lo durante a noite e cuidar da sua saúde, levando-o ao médico, dando-lhe remédio ou observando hábitos de higiene e prevenção de doenças: "A primeira coisa foi trocar [as fraldas] e eu troquei, me saí muito bem, me surpreendi até" (P33); "Eu chego em casa e eu que dou o banho nele" (P23); "Ela [mãe] faz eu pegar ele no berço [durante a noite]. (...) Eu vou e pego, faço ele arrotar, largo no berço, espero ele dormir e ela tá dormindo. Pego as coisas para mudar ele, pego fralda, mudo ele” (P38). Alguns pais também referiram fazer o bebê dormir, acalmá-lo, vesti-lo, participar no período de sua adaptação na creche e levá-lo e buscá-lo na creche: "Se eu vejo que ela já tá com sono, faço ela dormir” (P2).

A maioria dos pais (26) expressou dificuldades e/ou um sentimento de incompetência frente ao manejo do bebê. Destacaram-se as dificuldades em acalmar o bebê quando ele chorava, em atender as suas necessidades, fazê-lo dormir, segurá-lo no colo e/ou trocar fraldas: "Eu já troquei as fraldas, só que eu não tenho muita habilidade, é meio complicado" (P1). Um dos pais relatou ter dificuldades em limpar a sua filha, na troca de fralda, por ela ser menina. Também foi citada a dificuldade de dar banho e de vestir o bebê, a qual, muitas vezes, estava relacionada ao medo de machucá-lo. Alguns pais referiram ainda falta de paciência ou de motivação para atender o bebê: "Às vezes falta um pouco de paciência pra fazer tudo que ele quer, na hora que ele quer" (P22). Muitos pais destacaram que, frente a estas dificuldades, deixavam o bebê aos cuidados da mãe, vista como mais competente por ser mais habilidosa ou por ter mais tempo com o bebê: "Não consigo porque ele é molinho, se mexe, eu tenho medo de machucar ele, os bracinhos e passar a camisetinha pela cabecinha dele, eu tenho medo de machucar ele. Então eu já deixo pra mãe que a mãe já tem mais experiência” (P7).

Quase todos os pais (34) pais relataram brincar com seu bebê. Os tipos de brincadeiras citados foram brincadeiras motoras ou com o corpo do bebê, como cócegas, danças, brincadeiras com objetos, como brinquedos, com parte do corpo do pai, além de conversas. Os participantes demonstraram intenso prazer e satisfação no relato destas atividades: "Ele gosta de ficar deitadinho e eu mexendo na barriguinha dele, faço ele rir" (P12); "Eu brinco com ela bastante e ela sempre me dá retorno, um retorno bastante grande, ela também gosta de brincar" (P18). Vários pais também mencionaram levar o bebê para passear em parques, praças, sair de carro, de ônibus ou caminhando com o bebê em outros lugares: "Pegar ela [a filha] e ficar perambulando com ela. (...) Ficar passeando mesmo, sair, pular, caminhar"'(P13). A maioria dos pais (21) destacou conversar com o bebê, seja para interagir com ele, acalmá-lo ou aproximar-se dele imitando suas vocalizações: "Quando eu chego em casa é falar com ela, ver se ela vai me dar um sorriso. (...) Eu chego em casa e descrevo como se ela tivesse me contando o dia dela, eu chego e falo: 'Ah papai, hoje de manhã eu levantei, a minha mãe me deu mamá' (...) Ela fica super faceira, ela ri, fica super contente quando eu faço isso" (P18).

Poucos pais (7) relataram realizar atividades para distrair o bebê, mostrando a ele algum objeto ou paisagem, vendo televisão, cantando ou escutando música: "Eu gosto de sentar com ela de frente da televisão, ela fica às vezes assistindo uns negócios lá, ela olha os movimentos, as cores, assim, eu coloco um desenho, eu adoro ficar vendo com ela as caretas, as coisas que ela faz" (P15). Ainda poucos pais (8) referiram demonstrar afeto pelo filho/a através de abraços, beijos, carícias e massagens que faziam no bebê: "É bom ficar beijando o rosto assim, a sensação é boa (...) dá a sensação de que ele mesmo tá beijando, abraçar, de ficar tocando nele" (P24). Um dos pais ainda relatou ficar olhando carinhosamente para o bebê, apreciando-o. Além destas situações, cinco pais afirmaram realizar atividades com o intuito de estimular o desenvolvimento das habilidades físicas e/ou cognitivas do bebê, ensinando movimentos, incentivando o balbucio, apresentando objetos e outros estímulos: "Eu fico estimulando ela, perguntando as coisas, comentando, falando e ela começa a botar a voz pra for a como se quisesse falar” (P18).

Com relação à pergunta "O que você mais gosta de fazer com o bebê??", a atividade preferida pela maioria dos pais (15) foi brincar com o filho/a: "Eu gosto de ficar brincando com ela. Eu faço um barulhinho com a boca e ela tenta fazer igual. Acho isso legal" (P30). Outras atividades relatadas pelos pais foram: conversar com o bebê (9); levá-lo para passear (7); dar banho no bebê (4); o distrair (4); e pegá-lo no colo (4): "Eu fico conversando com ela. Lógico que entendo quando ela fica vidrada, dependendo do tipo de som que eu falo ela responde com um som semelhante, isso é uma habilidade que ela tem" (P8). As atividades fazer o filho/a dormir e demonstrar afeto foram citadas, cada uma, por apenas dois pais como sua atividade preferida com o bebê. Ainda foram referidas por alguns participantes como atividades preferidas trocar fraldas, dormir com o bebê e admirá-lo, cada uma citada por um pai: "Ficar curtindo ele, olhando ele, eu faço muito isso quando eu posso de ficar olhando ele e curtindo, os traços dele. Todo mundo diz que é parecido comigo, então eu fico ali, babando em cima!” (P27).

Com relação à pergunta "O que você menos gosta de fazer com o bebê?", as respostas dos pais envolveram uma grande variedade de situações, sendo que as atividades mais referidas como menos prazerosas foram acalmar o bebê (5), trocar suas fraldas (4), fazê-lo dormir (3) e acordar à noite para atendê-lo (3). Outras atividades referidas, cada uma por um participante, envolviam situações como fazer o bebê arrotar, vaciná-lo, limpar o seu nariz, dar remédios a ele, dar o banho, ficar com o bebê no colo quando este se mexia muito, ficar acordado até mais tarde com o bebê e levá-lo para cama depois que a mãe dava-lhe o peito à noite. Alguns pais destacaram os motivos pelos quais não apreciavam estas atividades. Estes incluíam a falta de habilidade e paciência ou a grande quantidade de tempo despendida para realizar a atividade, o cansaço, o sono e a dificuldade: "Trocar fralda, 
Tabela 1. Porcentagem e frequência de respostas para a categoria Interação com o bebê $(\mathrm{N}=38)$

\begin{tabular}{|c|c|c|}
\hline Interação com o bebê & $\begin{array}{l}\text { Número } \\
\text { de pais }{ }^{1}\end{array}$ & $\begin{array}{c}\text { Total de } \\
\text { respostas }^{2}\end{array}$ \\
\hline Cuidar/Atividade não específica & $89 \%(34)$ & 92 \\
\hline Trocar fraldas & $73 \%(28)$ & 51 \\
\hline Dar banho & $55 \%(21)$ & 42 \\
\hline Pegar no colo & $47 \%(18)$ & 36 \\
\hline Alimentar/dar mamadeira & $39 \%(15)$ & 21 \\
\hline Atender durante a noite & $34 \%(13)$ & 17 \\
\hline Fazer dormir & $31 \%(12)$ & 20 \\
\hline Cuidados com saúde & $31 \%(12)$ & 16 \\
\hline Acalmar & $26 \%(10)$ & 24 \\
\hline Vestir & $10 \%(4)$ & 4 \\
\hline $\begin{array}{l}\text { Participação na adaptação à } \\
\text { creche }\end{array}$ & $5 \%(2)$ & 3 \\
\hline Levar/buscar na creche & $2 \%(1)$ & 2 \\
\hline Dificuldades com cuidados & $68 \%(26)$ & 63 \\
\hline Brincar & $89 \%(34)$ & 82 \\
\hline Conversar & $55 \%(21)$ & 39 \\
\hline Passear & $36 \%(14)$ & 20 \\
\hline Demonstrar afeto & $21 \%(8)$ & 12 \\
\hline Distrair & $18 \%(7)$ & 11 \\
\hline Estimular & $13 \%(5)$ & 8 \\
\hline Total & 38 & 564 \\
\hline
\end{tabular}

${ }^{1}$ Cada pai pode ter apresentado respostas classificadas em mais de uma categoria; ${ }^{2}$ Cada pai pode ter apresentado mais de uma resposta classificada na mesma categoria ao longo da entrevista.

a fralda é terrivel, eu não tenho jeito pra coisa. Já troquei uma vez, mas não deu certo" (P1); "Na hora do choro, a gente tem que acordar e interromper o sono. Eu fico às vezes bem irritado com isso" (P13).

\section{Acessibilidade para o Bebê}

Esta categoria compreende os relatos dos pais sobre sua disponibilidade de tempo e atenção para a família e para o bebê, mas não necessariamente realizando atividades de interação com ele ou auxiliando a mãe. Desta forma, os pais podiam estar simplesmente fazendo companhia ao filho/a (estar junto). A classificação abarca duas subcategorias: quantidade de tempo com o bebê e avaliação do tempo com $o$ bebê. Como explicitado na Tabela 2, quase todos os pais (32) fizeram relatos sobre o tempo que tinham para dedicar ao bebê. A maioria deles referiu ter os finais de semana e as noites, durante a semana, para conviver com o bebê, pois trabalhavam o dia inteiro. Dois pais ainda estudavam à noite, depois do trabalho, podendo conviver com o bebê somente no final de semana. Alguns pais conseguiam almoçar em casa ou dar "fugidas" durante o expediente para ver o filho/a. Outros pais ficavam com o bebê algumas horas durante o dia, seja por trabalhar durante a noite ou em somente um turno, ou porque trabalhavam em casa, situações que permitiam a eles passar o dia mais próximo do bebê.

Vários pais (14) avaliaram dedicar pouco tempo ao bebê no seu dia-a-dia, relatando os motivos desta restrição, os seus sentimentos frente à situação e/ou descrevendo seus momentos com o bebê. Em grande parte, o pouco tempo disponível para o bebê devia-se à carga horária de trabalho e atividades de estudo. Alguns pais sentiam que o pouco tempo os impedia de ter maior participação nos cuidados e na rotina do bebê, enquanto outros salientaram que o cansaço decorrente da longa jornada de trabalho dificultava este envolvimento quando estavam com a família. Quatro pais verbalizaram explicitamente que gostariam de ter mais tempo para se dedicarem ao bebê e à esposa: "É tanta coisa que não dá nem tempo de parar para pensar de tanta correria no trabalho, na faculdade. (...) Eu acho que eu participo pouco, por essa questão de tempo eu participo muito pouco, tanto com ele [o filho] quanto com a K. [esposa]. Queria estar mais tempo com eles" (P24). Um dos participantes considerava que não acompanhava o desenvolvimento e as aquisições do filho devido ao pouco tempo e outro destacou sentir saudades do bebê em função do afastamento diário: "O trabalho está desgastante. Então eu sinto assim, cada vez que eu vejo ele, ele já tá maior e eu não tô... eu não tô passando todas as fases assim sabe. (...) Eu chego em casa e ela [mãe] me conta as coisas: 'Ele fez isso, ele fez aquilo'. Eu queria tá junto, pena que eu não tô junto, eu digo: 'Bah, porque quê eu não passo o dia inteiro com ele?" (P27).

Ainda quanto à avaliação do tempo com o bebê, mais da metade dos pais (22) salientou que estavam acessíveis para auxiliar a mãe, descrevendo momentos em que auxiliavam a mãe a cuidar do bebê, realizando atividades como preparar o banho, fazer e/ou alcançar a mamadeira, levar o bico, os produtos de higiene para troca de fraldas ou realizar atividades domésticas. Um dos pais relatou levar o bebê para que a mãe o amamentasse durante a noite. Enquanto alguns pais referiram que realizavam estas atividades por solicitação da companheira, outros o faziam por iniciativa própria, sendo que dois destacaram que já tinham uma divisão de tarefas estabelecida pelo casal: "Sempre que precisa eu ajudo ela. (...) Para pegar as coisas, quando ela não tem na mão, sempre solicita ajuda e, às vezes, eu observo que falta alguma coisa

Tabela 2. Porcentagem e frequência de respostas para a categoria Acessibilidade para o bebê $(\mathrm{N}=38)$

\begin{tabular}{lcc}
\hline Acessibilidade para o bebê & $\begin{array}{c}\text { Número de } \\
\text { pais }^{1}\end{array}$ & $\begin{array}{c}\text { Total de } \\
\text { respostas }^{2}\end{array}$ \\
\hline Quantidade de tempo com o bebê & $\mathbf{8 4 \% ~ ( 3 2 )}$ & $\mathbf{7 1}$ \\
\hline Avaliação do tempo com o bebê & & \\
Pouco tempo & $36 \%(14)$ & 32 \\
Acessível para auxiliar a mãe & $57 \%(22)$ & 35 \\
\hline Total & $\mathbf{3 8}$ & $\mathbf{1 3 8}$ \\
\hline
\end{tabular}

' Cada pai pode ter apresentado respostas classificadas em mais de uma categoria; ${ }^{2}$ Cada pai pode ter apresentado mais de uma resposta classificada na mesma categoria ao longo da entrevista. 
e busco" (P5). Enquanto dois pais revelaram sentirem-se irritados com algumas solicitações da esposa, outros dois participantes expressaram satisfação por ajudar: "Ela [a esposa] está trocando a F., aí ela diz assim: 'me alcança uma fralda'. Eu vou lá e pego a fralda, aí: 'me alcança o creme'. Por que ela não me pediu a fralda e o creme então? Entendeu? Uma coisa perto da outra, ai lá vou eu, por que já não pede tudo de uma vez? Às vezes eu me irrito com essas coisas" (P15).

\section{Responsabilidades e Preocupações com o Bebê}

Esta categoria abarca os relatos dos pais sobre as responsabilidades que assumiam com o bebê no que diz respeito a sua participação e influência direta na rotina, em aspectos educativos e de cuidado, assim como suas preocupações com os filhos. Quanto às responsabilidades, destacaram-se quatro subcategorias: participação nas decisões sobre o bebê; mãe como principal responsável; aumento das responsabilidades; e, conversar com a mãe sobre aspectos do cuidado/educação do bebê. Quanto às preocupações destacam-se: com o cuidado do bebê por outras pessoas; com a educação do filho; em ser bom pai; com a saúde do bebê; com a sobrecarga da esposa; com o futuro do filho; e com o sustento financeiro da família. A Tabela 3 apresenta as porcentagens e frequências para cada categoria e subcategoria.

A quase totalidade dos pais percebia que o nascimento do seu primeiro filho/a trouxe responsabilidades (35) e preocupações (36). Quanto a isso, quase todos os pais (31) afirmaram participar das decisões a respeito de como e por quem o bebê seria cuidado. Para tanto, os pais consideraram a disponibilidade de familiares para ficar com o bebê, os seus horários de trabalho, o custo financeiro das alternativas e as crenças a respeito do que seria melhor para o filho: " $E u$ tenho mais confiança em deixar aqui com a minha sogra" (P11); "Mas a gente não sabe ainda, porque também não tem como só ficar com as avós, as avós também têm as vidas delas, então esta parte aí a gente não sabe se a gente contrata alguém, isso ai é... essas decisões assim, são difíceis" (P33). Quando a decisão era colocar o bebê em uma creche, nove pais afirmaram contribuir na decisão sobre a idade em que isso ocorreria e sobre qual escola. Outro participante referiu participar da decisão sobre se o bebê dormiria no seu próprio quarto ou com os pais.

Diversos pais (17) salientaram as mudanças trazidas pelo nascimento do bebê, considerando a necessidade de priorizá-lo, adaptar-se ao seu ritmo e dedicar-se a ele constantemente, tendo em vista a sua total dependência dos pais: "Sempre tendo a consciência que em casa tem um nenê que precisa de mim, e por muitos anos ainda vai precisar de mim" (P8). Neste sentido, um pai destacou o caráter definitivo das responsabilidades e preocupações, enquanto outros dois enfatizaram a mudança de status proporcionada pelo nascimento de seu filho/a: "Estou me sentindo diferente, assim no trabalho eu achei que eu tô diferente, tô pensando mais que eu tenho uma família agora, antes que eu tinha só a J. [esposa], a gente não pensava tanto como uma família, hoje a gente pensa muito mais como uma família” (P18).
Contudo, vários pais (17) destacaram que a companheira tinha a maior responsabilidade pelos cuidados do bebê, seja por que ela realizava mais tarefas ou porque havia atividades que lhe eram exclusivas (principalmente ligadas à higiene e alimentação). Muitos destes pais acreditavam que isto acontecia porque a mãe dedicava mais tempo ao bebê. Em alguns casos, este fato se devia ao período de licença maternidade: "Ela [mãe] que passa a maior parte do tempo com ele. (...) Quando eu chego em casa, ela já fez tudo” (P38). Um dos participantes atribuiu a maior responsabilidade da mãe pelo cuidado da filha à proximidade da relação mãe-bebê durante o período de amamentação: "Tu não tem como interferir na relação mãe e filha. Elas estão muito próximas, ela mama no peito da mãe umas dez vezes por dia. (...) Então a participação do pai é mais afastada, mas mesmo assim eu procuro estar sempre presente" (P8).

Vários pais (13) relataram diálogos do casal, fossem estes amistosos ou conflituosos, sobre aspectos do cuidado e educação do bebê, tais como a maneira de lidar com ele e a escolha pela forma de cuidado alternativo. Um dos pais acreditava que conversar com a mãe sobre a filha era uma forma de participar indiretamente do seu cuidado e dia-a-dia, já que passava pouco tempo em casa: "A gente tem trocado muita ideia porque eu não posso estar ao longo da semana com ela [bebê], a maior parte do tempo. As coisas que talvez eu gostaria de fazer, ela [mãe] tem feito por mim, as coisas que a gente procura dar, cuidados " (P25). Dois pais referiram discutir sobre a participação da família extensa nos cuidados com o bebê, demonstrando insatisfação por considerarem que havia interferência excessiva de familiares da esposa: "Eu e a C. [mãe] a gente conversou: 'Olha, agora o negócio é o seguinte, quando a T. [bebê] estiver chorando, alguém tem que parar e dar atenção para ela'. Porque é criança, ela precisa de nós" (P3); "Eu até disse para a A. [mãe], quando for ver essa creche tem que ver com quem vai ficar, tem que ver bem, sabe. Ser bem xarope sobre isso aí, como é que é, onde ele [bebê] vai ficar" (P7).

Quanto às preocupações, a maioria dos pais referiu preocupar-se sobre algum aspecto do cuidado do bebê por outras pessoas, como familiares, babás ou professoras da escola, mesmo em situações em que este não ocorria de forma sistemática ou que fosse acontecer num futuro próximo, quando a mãe voltasse a trabalhar ou estudar. As preocupações se referiram à higiene, segurança, saúde, bem-estar psicológico e desenvolvimento do bebê. Oito pais destacaram sua discordância com algum aspecto das práticas de cuidado do bebê por parte do cuidador e um destes pais apontou sua insatisfação com a intrusão demasiada dos sogros nos cuidados da filha: "Estávamos pensando em uma pessoa para ficar aqui. Mas aí até o meu pai achou meio complicado, botar uma pessoa que a gente não conhece, que a minha mãe ia ter que vir aqui toda hora dar aquelas incertas para ver como é que andavam as coisas. Então que ficaria melhor deixar [o bebê] lá com a minha mãe. Por enquanto ele é muito novinho" (P12); “Algumas coisas só que eu fico bem preocupado, que eu não gosto muito. Por exemplo, quando os avôs e as avós, falam: 'Ah, você devia dar isso, aquilo'. Começam a dar opinião quanto à alimentação” (P25).

As preocupações dos pais com a ida do bebê para a creche incluíam o temor de que o maltratassem, de que ele 
não recebesse uma boa atenção e cuidado e de como ele iria reagir aos períodos longe de casa. Assim, três pais declararam que não gostariam de colocar o bebê na creche e outros dois afirmaram desejar que somente a mãe cuidasse da criança: "Então eu já fico meio assim, com medo [de colocar na creche]. Será que as pessoas vão cuidar bem dele? Será que vão dar atenção para ele? Claro que a pessoa não vai ficar ali só cuidando dele, tem outras crianças, mas eu já fico pensando: Será que vão maltratar?" (P7). Muitos pais (24) expressaram sentimentos de ciúmes, saudade, insegurança, medo e até desconfiança frente ao cuidado do filho/a por outras pessoas naquele momento ou num futuro próximo: "Ciúme é normal. A gente está aqui conversando, mas fica cuidando para ver se a pessoa está cuidando direito, se pega direito, porque é meu [filho], o cara tá cuidando ali, mas eu não descuido, sou um pouco superprotetor" (P1). Todavia, pelo menos nove pais manifestaram satisfação, tranquilidade e confiança com relação ao cuidado que o bebê estava recebendo ou que logo receberia: "Ele vai estar numa creche boa. Eu fico mais tranquilo do que deixar em casa. Apesar de que essa empregada eu gosto, tudo, mas eu acho que uma creche tem mais responsabilidade. (...) Não pode deixar acontecer qualquer coisa" (P36).

Muitos pais (17) expressaram atenção com a educação do/a filho/a, tanto no que diz respeito ao momento atual, preocupando-se em estimular o seu desenvolvimento cognitivo e social, quanto em relação ao futuro, preocupando-se em prepará-lo para as responsabilidades da vida adulta e dar-lhe estudo: "Tem o lado da responsabilidade (...) no mínimo proporcionar pra ele uma boa educação em casa e também na vida" (P14). Muitos destes pais (13) consideraram que a creche era importante para o desenvolvimento do bebê, pois facilitaria a convivência com outras crianças e a aprendizagem de regras e limites, complementando a educação recebida em casa. Apesar de avaliarem, geralmente, a ida para a creche como algo positivo, dois pais declararam ter receio por deixar o/a filho/a na escolinha: "Ela vai estranhar no início, isso é óbvio, mas é até bom para ela se socializar" (P17); "Ali não vai ser o centro das atenções, vai ter outras crianças, vai disputar. O mundo é assim, é uma preparação para o mundo a creche. Embora tenha os lados negativos" (P25).

Vários pais (12) demonstraram uma preocupação em serem bons pais, evitando erros ou falhas e buscando aproximar-se o máximo possível de seu ideal de paternidade. Estes pais referiram o desejo de transmitir para o filho seus conhecimentos e características positivas, de serem vistos por ele como uma pessoa correta e de que nada faltasse à criança: "Olha, eu vou tentar assim, passar o melhor pra ela. O que eu aprendi com meus pais, tentar passar o melhor pra ela" (P3). Outros participantes também se preocupavam em dar atenção e carinho para o bebê, ajudar a cuidá-lo e fazerem-se presentes: "Tudo o que eu puder passar para ele, eu vou passar, assim, as coisas boas, como pai, para que ele possa ter o carinho meu, o amor para poder viver, não ficar com aquela impressão de que não foi amado, não foi criado com carinho" (P4).

A preocupação com a prevenção ou tratamento de problemas de saúde do bebê também foi referida por vários pais (11) e incluiu pontos como os cuidados com o ganho de peso do bebê, alimentação, exposição ao sol, evacuações e reações às vacinas. Entre estes, alguns afirmaram colocar regras para os visitantes do bebê (como lavar as mãos e não fumar), seguir as orientações do pediatra e evitar colocar o bebê na creche para que ele não ficasse doente: "Eu procuro fazer a orientação tudo certa com o pediatra dela, com a enfermeira que atende ela" (P2); "Em creche a gente não gostaria de deixar porque ele é muito pequeno, até o próprio pediatra disse 'Se tu vai deixar numa creche, toda semana [o bebê] vai ter alguma coisa"', (P33).

Alguns pais (8) preocupavam-se com o desgaste físico e/ ou emocional da esposa, já que ela assumia quase todos os cuidados com o bebê e ficava a maior parte do tempo com ele. Em particular, um dos pais acreditava que o período de amamentação exigia muita dedicação da mãe, sendo algo cansativo. Dois pais salientaram que, além dos cuidados com o bebê, a esposa assumia as tarefas domésticas, o que a sobrecarregava com mais atividades. Estes pais expressaram sentimentos de empatia, compreensão e culpa pela situação de estresse experimentada pela mãe: "Eu acho que é muito mais responsabilidade como mãe. Às vezes eu gostaria muito de poder tirar assim, o peso que ela tem, principalmente quando tava amamentando. Quando tá o dia todo em função do bebê, para mãe é muito desgastante. E ainda tem aquela

Tabela 3. Porcentagem e frequência de respostas para a categoria Responsabilidades e preocupações com o bebê $(\mathrm{N}=38)$

\begin{tabular}{|c|c|c|}
\hline $\begin{array}{c}\text { Responsabilidades e } \\
\text { preocupações com o bebê }\end{array}$ & $\begin{array}{l}\text { Número } \\
\text { de pais }\end{array}$ & $\begin{array}{c}\text { Total de } \\
\text { respostas }^{2}\end{array}$ \\
\hline Responsabilidades & $92 \%(35)$ & 100 \\
\hline Participação nas decisões & $81 \%(31)$ & 60 \\
\hline $\begin{array}{l}\text { Mãe como principal } \\
\text { responsável }\end{array}$ & $44 \%(17)$ & 29 \\
\hline $\begin{array}{l}\text { Aumento das } \\
\text { responsabilidades }\end{array}$ & $44 \%(17)$ & 22 \\
\hline $\begin{array}{l}\text { Conversa sobre cuidado/ } \\
\text { educação }\end{array}$ & $34 \%(13)$ & 18 \\
\hline Preocupações & $92 \%(36)$ & 145 \\
\hline Cuidado por outras pessoas & $78 \%(30)$ & 68 \\
\hline Educação do filho & $44 \%(17)$ & 25 \\
\hline Em ser um bom pai & $31 \%(12)$ & 17 \\
\hline Saúde & $29 \%(11)$ & 12 \\
\hline Sobrecarga da esposa & $21 \%(8)$ & 10 \\
\hline Futuro do filho & $15 \%(6)$ & 8 \\
\hline $\begin{array}{l}\text { Sustento financeiro do } \\
\text { filho }\end{array}$ & $13 \%(5)$ & 5 \\
\hline Total & 38 & 274 \\
\hline
\end{tabular}

${ }^{1}$ Cada pai pode ter apresentado respostas classificadas em mais de uma categoria; ${ }^{2}$ Cada pai pode ter apresentado mais de uma resposta classificada na mesma categoria ao longo da entrevista. 
relação de mamar, que é lógico, é um grande prazer mas, por outro lado, também tu tá desgastado e aí o nenê, tipo assim, te suga. (...) Ela tá bastante estressada e desgastada por causa disso também” (P9). Frente a isso, dois participantes relataram incentivar o retorno da esposa ao trabalho para que ela buscasse sua realização profissional: " $A$ minha esposa quer voltar a trabalhar, ela tem que trabalhar. (...) Não dá só para deixar para a mulher, só depois vai trabalhar fora, vai cuidar dela [bebê] em casa, porque é cansativo. Barbaridade, cuidar de criança é cansativo" (P37).

Seis pais referiram preocupações com o futuro de seu filho, expressando o desejo de que ele/a tivesse um bom caráter, escolhesse uma boa profissão e tivesse melhores oportunidades na vida do que as que teve: "Eu acho que eu não tive muitas oportunidades que nem ela vai ter, e acho que eu sempre vou dar mais oportunidades para ela" (P5). Um pai preocupava-se com a época em que sua filha começasse a sair à noite, e outro pai temia que seu filho pudesse envolver-se com drogas. Um pai ainda afirmou desejar que a filha fosse, no futuro, melhor que o pai no controle das emoções: "Souber fazer o que eu não consigo fazer (...) dela saber dominar esse lado dela, esse lado explosivo” (P2). Outros cinco pais manifestaram apreensões relativas a manterem o sustento da família e em proporcionar ao filho maior conforto e oportunidades: "Eu acho que o meu medo maior é, assim, é proporcionar a ele coisas que ele quer. De repente, alguma coisa material, “eu quero isso, quero aquilo” e eu não poder proporcionar tudo” (P14).

\section{Discussão}

Até algumas décadas atrás, as pesquisas empíricas abordavam o papel e importância do pai sobre o desenvolvimento da criança somente em um período posterior à primeira infância, associando-o a aspectos como a competência cognitiva e social e, particularmente, em relação aos filhos do sexo masculino (Lebovici, 1987). Embora se observe uma maior preocupação com a paternidade nos últimos anos, no período que compreende os primeiros meses após o nascimento do bebê ainda predominam estudos que enfocam a maternidade. O presente estudo buscou investigar o envolvimento paterno durante os primeiros três meses de vida do bebê, baseando-se nas três dimensões do conceito de envolvimento paterno (Lamb et al., 1985) a saber: interação, acessibilidade e responsabilidade do pai para com seu filho.

Os achados do presente estudo apontaram que muitos pais estavam envolvidos em atividades de interação e cuidados com o bebê, estando acessíveis a ele e à mãe, além de compartilhar responsabilidades e preocupações em relação ao cuidado, educação e sustento da criança. Quanto à interação direta com o bebê, muitos pais relataram se envolver em diversas tarefas de cuidado, como dar atenção e ficar com o bebê, trocar fraldas e roupas, dar o banho, fazer o bebê dormir ou acalmá-lo. Mesmo que estas atividades fossem desempenhadas, por vezes, de maneira eventual, os resultados demonstram a disponibilidade ou o esforço de pelo menos uma parte dos pais em envolverem-se com os cuidados do bebê. Estes dados parecem endossar a literatura que indica uma mudança no envolvimento dos pais na criação dos filhos pequenos, em especial entre pais que tem seu primeiro filho (Ninio \& Rinott, 1988; Pleck, 1997; Rustia \& Abott, 1993; Yeung, Sandberg, Davis-Kean \& Hofferth, 2001).

Ao mesmo tempo, um número expressivo de pais referiu dificuldades em desempenhar estas atividades, indicando que a sua participação nos cuidados do bebê pode incluir sentimentos de inexperiência e inadequação. Pesquisas destacam que frente a um bebê pequeno e que demanda, prioritariamente, cuidados, os pais podem sentir-se confusos e deslocados, já que muitos imaginavam o filho como amigo e companheiro de brincadeiras e esperavam uma interação mais recíproca com ele (Barclay \& Lupton, 1999; Goodman, 2005). Deste modo, apesar de muitos pais terem por vezes, expectativas de grande envolvimento na educação e nos cuidados diretos com o bebê ainda na gestação, isto não necessariamente se traduzirá em uma maior participação nos cuidados nos seus primeiros meses de vida (Garfield \& Chung, 2006).

Em consonância com estas ideias, os participantes do presente estudo deram destaque às atividades não-relacionadas aos cuidados, como brincar, conversar e passear com o bebê, as quais eram preferidas por muitos deles e experimentadas com satisfação e alegria. Neste sentido, estudos apontam que os pais tendem a diferenciar seus deveres dos deveres da mãe com uma criança pequena, privilegiando o papel de companheiro de brincadeiras do filho e de disciplinador, ao invés do papel de provedor de cuidados (Bailey, 1994; Delmore-Ko, Pancer, Hunsberger \& Pratt, 2000; Garfield \& Chung, 2006). Para a maior parte dos pais do presente estudo, a mãe permanecia como a responsável principal pelos cuidados do bebê, sendo que muitos consideram estas tarefas difíceis e acreditavam que não tinham habilidades suficientes para desempenhá-las. Assim, as brincadeiras, conversas e passeios davam aos pais a sensação de uma maior conexão emocional, auto-estima e intimidade com o bebê, na medida em que forneciam interações recíprocas e prazerosas para ambos, o que está em concordância com os achados de outros autores (Anderson, 1996; Goodman, 2005; Rezende \& Alonso, 1995).

No que diz respeito à acessibilidade, todos os pais demonstraram estar disponíveis ao bebê e/ou para ajudar a esposa em algum período do dia, embora a quantidade de tempo que era despendida com a família tenha variado bastante. A maior parte do tempo que os pais relataram disponibilizar ao bebê ocorria durante as noites nos dias de semana e, principalmente, aos finais de semana, achado que apóia a literatura (Yeung et al., 2001). Contudo, dentre os participantes do presente estudo, alguns pais trabalhavam em casa ou tinham horários de trabalho bastante flexíveis, o que lhes permitia estar mais tempo junto ao bebê. Por outro lado, muitos pais relataram que tinham o tempo com a família limitado em função do trabalho. Para estes pais, a grande carga horária de trabalho restringia o seu tempo e envolvimento com suas famílias e nas atividades cotidianas com os filhos, trazendo frustrações. Apesar de existirem muitas formas de envolvimento, o tempo é um aspecto importante para compreender a atenção e o cuidado, direto e indireto, investido na criança dentro do contexto familiar. Estudos sugerem que os pais se preocupam em gastar tempo com seus filhos, sendo esta uma prioridade para eles, embora saibam das dificuldades e custos que isso envolve (Daly, 1996; Nyström \& Öhrling, 2004; 
Sanderson \& Thompson, 2002). Assim, a falta de tempo com a família, o cansaço e, além disso, a sensação de que estavam perdendo momentos importantes do bebê sobrecarregavam muitos destes pais e, em consonância com outros estudos, constituíam-se em uma barreira ao envolvimento nos cuidados com o bebê (Corwyn \& Bradley, 1999; Garfield \& Chung, 2006). Assim, entende-se que as demandas de trabalho podem não somente restringir o tempo com o bebê, como também limitar a oportunidade de conhecê-lo melhor e de adquirir habilidades para o seu cuidado. Além disso, a preocupação dos pais do presente estudo com o pouco tempo dedicado à família podem refletir a busca por ajustar-se ao ideal de bom pai que, muitas vezes, associa-se à ideia de dedicar mais tempo à criança e estar presente na sua rotina (Daly, 1996).

Quanto às responsabilidades que os pais relataram assumir com os filhos, destacaram-se as preocupações relativas à qualidade do cuidado provido por outras pessoas e a ansiedade em deixar o bebê com outros cuidadores, o que também foi encontrado em outros estudos (Anderson, 1996; Nyström \& Öhrling, 2004). Nesta direção, alguns pais expressaram que o cuidado fornecido pela companheira ao bebê era o mais adequado, o que pode sugerir que os pais delegam à mãe a principal responsabilidade pelos cuidados do filho (Nyström \& Öhrling, 2004). Mesmo assim, apesar de muitos pais não assumirem, de forma sistemática, atividades diretas de cuidado, a grande referência a preocupações com o cuidado do bebê, sua entrada na creche, sua educação e seu futuro, assim como discutir e decidir com a companheira aspectos do cuidado do bebê, marcam um tipo de envolvimento e participação destes pais na rotina da família. Além disso, muitos participantes afirmaram experimentar um aumento de suas responsabilidades e preocupações após o nascimento do bebê, referindo também mudanças e adaptações que precisaram realizar na sua vida. Estes relatos salientaram o momento de transição vivido pela família durante o primeiro trimestre de vida de seu primeiro filho. Stern (1997) afirmou que o nascimento de um filho, em especial o primeiro, provoca profundas mudanças não somente na rotina do casal e na vida conjugal, mas no mundo representacional dos pais e mães, os quais precisam re-elaborar as redes subjetivas que compõem sua identidade.

Neste sentido, os relatos de alguns pais apontaram que a prática da paternidade pode ser acompanhada por sentimentos de desconforto e insatisfação frente às dificuldades em desempenhar determinadas tarefas com o bebê ou por não ter mais tempo com ele. Se, por um lado, estas vivências podem relacionar-se a dificuldades individuais do próprio pai, por outro lado, estas podem também corresponder a uma mudança no ideal cultural de pai, o qual impõe um maior envolvimento com os filhos e uma divisão mais igualitária das responsabilidades com a criança entre mães e pais (Barclay \& Lupton, 1999; Henwood \& Procter, 2003; Lewis \& Dessen, 1999). Neste caso, haveria uma tensão entre a esfera profissional e familiar, sendo que a conciliação entre as demandas destes dois papéis se torna difícil para muitos pais. Alguns autores apontam que a noção de um novo pai tem provocado diversos paradoxos e tensões que influenciariam as formas como os homens vêem a si mesmos como pais e como desempenham a paternidade (Lupton \& Barclay, 1997; Niström \& Öhrling, 2004). Ao mesmo tempo em que este novo ideal de pai seria uma oportunidade para o homem expressar seus sentimentos de proteção e intimidade com o filho, desempenhando um papel mais igualitário na parentalidade, a identidade masculina permanece centrada, prioritariamente, no trabalho e no papel de provedor financeiro da família. É possível ainda que aspectos da cultura ocidental oportunizem pouco engajamento dos pais na criação de seus filhos pequenos, a partir de práticas sociais que colocam o cuidado de um bebê como um domínio feminino (Anderson, 1996; Hewlett, 2000).

É importante destacar ainda que, aos três meses de vida de seu primeiro filho, os pais encontravam-se ainda em um momento de transição familiar, quando procuravam adaptar-se à realidade do bebê e às suas características, ao papel de pai e às mudanças na relação conjugal (Brazelton \& Cramer, 1992; Stern, 1997). Além disso, alguns pais do estudo consideravam que a mãe tinha uma posição privilegiada na relação com o bebê, seja pela amamentação no seio, pela maior responsabilidade nos cuidados e/ou por ter mais tempo com ele, o que pode denotar que se sentiam diminuídos ou colocados em segundo plano. Estudos têm encontrado que ciúmes, solidão e sentimentos de exclusão da relação entre mãe e bebê são comuns entre os pais, em especial durante as primeiras semanas após o nascimento, sendo que muitos deles acham que precisam se esforçar mais do que a mãe para atrair o bebê e marcar sua presença (Anderson, 1996; Ahlborg \& Strandmark, 2001; Goodman, 2005). No presente estudo, as preocupações de alguns participantes em serem bons pais, parecem também evidenciar a busca por seguir um ideal de paternidade e legitimar a sua importância.

Por outro lado, entende-se que a necessidade de adaptação da família ao nascimento do primeiro filho altera a divisão das tarefas pelo casal, podendo levá-lo a divisões de papéis de gênero mais tradicionais (Levy-Shiff, 1994). De acordo com o autor, neste período de transição familiar, mesmo entre casais em que ambos têm uma vida profissional ativa, a mulher tende a responsabilizar-se mais pelo bebê e pelas tarefas domésticas e o homem pelo sustento financeiro. Entretanto, no presente estudo, poucos pais referiram espontaneamente preocupações com o sustento da família, privilegiando a atenção a outros aspectos do cuidado da criança. Neste sentido, Trindade, Andrade e Souza (1997) colocam que as mudanças na divisão de papéis na vida familiar podem estar mais localizadas na qualidade da relação entre pais e filhos do que na paridade de participação entre pais e mães.

O apoio material e emocional fornecido pelo pai é fundamental para a constituição das primeiras relações entre mãe e filho, sendo um importante aspecto da função paterna neste período do desenvolvimento (Stern, 1997; Winnicott, 1960/1983). Neste sentido, frequentemente os homens tendem a ser vistos como desempenhando um papel secundário e de suporte de suas companheiras. Este aspecto foi salientado por alguns pais do presente estudo que destacaram sua preocupação com a sobrecarga física e emocional que o cuidado sistemático do bebê provocava nas companheiras. No entanto, o que ficou evidente através dos relatos dos pais é que eles também precisam de apoio em seus esforços para envolver-se não somente nos cuidados com o bebê, mas na construção de uma relação de afeto e de satisfação 
recíproca com o filho. Muitas vezes, a carência de modelos e a pouca atenção que os recém-pais recebem neste momento de transição para a parentalidade, quando o centro ainda é a díade mãe-bebê, pode contribuir para a um sentimento de insegurança frente à exigência de maior envolvimento nos cuidados diretos com o filho (Barclay \& Lupton, 1999; Goodman, 2005; Masciadrelli, Pleck \& Stueve, 2006). Os serviços de atendimento pré-natal, muitas vezes, priorizam a gestante e o bebê, excluindo o pai (Buist, Morse \& Durkin, 2003). E acredita-se que o mesmo pode ser dito em relação aos atendimentos no período pós-natal. Considera-se que a falta deste apoio poderá influenciar a transição psicológica para a paternidade e, portanto, merece atenção dos profissionais de saúde que atuam junto a essas famílias.

Além disso, é importante pontuar que as mães desempenham um papel crítico em promover ou dificultar o envolvimento dos pais com os filhos e, consequentemente, a relação pai-bebê (Anderson, 1996; Barclay \& Lupton, 1999). As mães podem facilitar a relação pai-bebê compartilhando de modo positivo seus sentimentos e sua experiência a respeito do cuidado do filho, oferecendo-se como modelos para seus parceiros e reconhecendo sua importância para o desenvolvimento do bebê. Elas ainda podem encorajar o envolvimento dos pais com os filhos dando informações sobre a sua rotina diária, seu desenvolvimento e oferecendo-lhe apoio emocional. Por outro lado, algumas mães podem dificultar ou restringir o envolvimento do pai, inibindo o desenvolvimento do papel parental no companheiro (Allen \& Hawkins, 1999).

De forma geral, os achados do presente estudo revelaram que um pai pode estar envolvido de muitas formas com o bebê no seu terceiro mês de vida, seja brincando, cuidando, ensinando, provendo suporte financeiro, demonstrando afeto, seja compartilhando com a mãe atividades, responsabilidades e preocupações a respeito da criança. Estes dados sugerem que, tanto em conjunto quanto de modo individual, os pais demonstraram diferentes níveis de envolvimento considerando cada uma das três dimensões do envolvimento paterno. Embora, na maior parte dos casos, a participação do pai esteja ainda aquém de uma paridade com a mãe, muitos participantes demonstraram um desejo de se envolver mais nos cuidados do bebê. Estes achados estão de acordo com outros estudos, os quais apontaram que, atualmente, os pais desejam ter uma maior participação na criação dos filhos e acreditam na sua capacidade de cuidar de crianças (Anderson, 1996; Rezende \& Alonso, 1995).

Deste modo, fica evidente a coexistência de diferentes papéis familiares assumidos pelos pais na atualidade, endossando a grande variabilidade e flexibilidade da concepção de paternidade (Doherty, Kouneski \& Erickson, 1998; Marsiglio, Amato, Day \& Lamb, 2000). Ao mesmo tempo, fica clara a necessidade de que as instituições em contato com pais e mães de bebês acompanhem a mudança do discurso social a respeito da paternidade e apóiem a família, em especial os pais, durante este período crítico de transição familiar. Acredita-se que esta nova concepção de pai, embora largamente difundida em nossa cultura, ainda carece de modelos mais claros, o que acaba exigindo que os homens criem seus próprios parâmetros de paternidade responsável e envolvida. Por fim, considera-se importante que outros estudos investiguem a experiência subjetiva da paternidade nos primeiros meses do filho, bem como as transformações nas questões relativas ao exercício da paternidade na sociedade atual.

\section{Referências}

Ahlborg, T., \& Strandmark, M. (2001). The baby was the focus of attention - first-time parents' experiences of their intimate relationship. Scandinavian Journal of Caring Science, 15(4), 318-325.

Allen, S., \& Hawkins, A. (1999). Maternal gatekeeping: Mothers' beliefs and behavior that inhibit greater father involvement in family work. Journal of Marriage and the Family, 61(1), 199-212.

Amato, P. R., \& Gilbreth, J. G. (1999). Nonresident fathers and children's well-being: A meta-analysis. Journal of Marriage and the Family, 61(3), 557-573.

Anderson, A. M. (1996). The father-infant relationship: Becoming connected. Journal of the Society of Pediatric Nurses, 1(2), 83-92.

Bailey, W. T. (1994). A longitudinal study of fathers' involvement with young children: Infancy to age 5 years. The Journal of Genetic Psychology, 155(3), 331-339.

Barclay, L., \& Lupton, D. (1999). The experience of new fatherhood: a socio-cultural analysis. Journal of Advanced Nursing, 29(4), 1013-1020.

Bardin, L. (1977). Análise de Conteúdo. São Paulo: Edições 70.

Belsky, J., Gilstrap, B., \& Rovine, M. (1984). The Pennsylvania Infant and Family Development Project, I: Stability and change in mother-infant and father-infant interactions in a family setting at one, three, and nine months. Child Development, 55(3), 692-705.

Brazelton, T. B. (1988). O desenvolvimento do apego: Uma família em formação. Porto Alegre: Artes Médicas.

Brazelton, T. B., \& Cramer, B. G. (1992). As primeiras relações. São Paulo: Martins Fontes.

Buist, A., Morse, C., \& Durkin, S. (2003). Men's adjustment to fatherhood: Implications for obstetric health care. Journal of Obstetric, Gynecologic and Neonatal Nursing, 32(2), 172-180.

Cabrera, N. J., Tamis-LeMonda, C. S., Bradley, R. H., Hofferth, S., $\&$ Lamb, M. E. (2000). Fatherhood in the twenty-first century. Child Development, 71(1), 127-136.

Corwyn, R. F., \& Bradley, R. H. (1999). Determinants of paternal and maternal investment in children. Infant Mental Health Journal, 20(3), 238-256.

Cramer, B., \& Palacio-Espasa, F. (1993). Técnicas psicoterápicas mãe-bebê. Porto Alegre: Artes Médicas.

Daly, K. J. (1996). Spending time with the kids: Meanings of family time for fathers. Family Relations, 45(4), 466-476.

Delmore-Ko, P., Pancer, S. M., Hunsberger, B., \& Pratt, M. (2000). Becoming a parent: The relation between prenatal expectations and postnatal experience. Journal of Family Psychology, 14(4), 625-640.

Doherty, W. J., Kouneski, E. F., \& Erickson, M. F. (1998). Responsible fathering: An overview and conceptual framework. Journal of Marriage and the Family, 60(2), 277-292. 
Easterbrooks, M. A., \& Goldberg, W. A. (1984). Toddler development in the family: Impact of father involvement and parenting characteristics. Child Development, 55(3), 740-752.

Garfield, C. F., \& Chung, P. J. (2006). A qualitative study of early differences in fathers' expectations of their child care responsibilities. Ambulatory Pediatrics, 6(4), 215-220.

Goodman, J. H. (2005). Becoming an involved father of an infant. Journal of Obstetric, Gynecologic, and Neonatal Nursing, 34(2), 190-200.

Grupo de Interação Social, Desenvolvimento e Psicopatologia (1998a). Ficha de Contato Inicial. Porto Alegre: Instituto de Psicologia, UFRGS. Instrumento não publicado.

Grupo de Interação Social, Desenvolvimento e Psicopatologia (1998b). Entrevista de Dados Demográficos do Casal. Porto Alegre: Instituto de Psicologia, UFRGS. Instrumento não publicado.

Grupo de Interação Social, Desenvolvimento e Psicopatologia (1999). Entrevista sobre a Experiência da Paternidade e o Desenvolvimento do Bebê no Primeiro Trimestre Porto Alegre: Instituto de Psicologia, UFRGS. Instrumento não publicado.

Henwood, K., \& Procter, J. (2003). The 'good father': Reading men's account of parental involvement during the transition to first-time fatherhood. British Journal of Social Psychology, 42(3), 337- 355.

Hewlett, B. S. (2000). Culture, history, and sex: Anthropological contributions to conceptualizing father involvement. Marriage \& Family Review, 29 (2/3), 59-73.

Hollingshead, A. B. (1975). Four factor index of social status. Unpublished manuscript, Department of Sociology. Yale University.

Houzel, D. (2004). As implicações da parentalidade. In L. SolisPonton (Ed.), Ser pai, ser mãe: Parentalidade: Um desafio para o terceiro milênio: Uma Homenagem internacional para Serge Lebovici (pp. 47-51). São Paulo: Casa do Psicológo.

Lamb, M. E. (Ed.) (1997). The role of the father in child development. New York: John Wiley.

Lamb, M. E., Pleck, J. H., Charnov, E. L., \& Levine, J. A. (1985). Paternal behavior in humans. American Zoologist, 25(3), 883-894.

Laville, C., \& Dione, J. (1999). A construção do saber. Porto Alegre: Artmed.

Lebovici, S. (1987). O bebê, a mãe e o psicanalista. Porto Alegre: Artes Médicas.

Levy-Shiff, R. (1994). Individual and contextual correlates of marital change across the transition to parenthood. Developmental Psychology, 30(4), 591-601.

Lewis, C., \& Dessen, M. A. (1999). O pai no contexto familiar. Psicologia: Teoria e Pesquisa, 15(1), 09-16.

Lupton, D., \& Barclay, L. (1997). Constructing fatherhood. Discourses and experiences. London: SAGE.

Marsiglio, W., Amato, P., Day, R. D., \& Lamb, M. E. (2000). Scholarship on fatherhood in the 1990s and beyond. Journal of Marriage and the Family, 62(4), 1173-1191.

Masciadrelli, B., Pleck, J., \& Stueve, J. (2006). Fathers' role model perceptions: Themes and linkages with involvement. Men and Masculinities, 9(1), 23-34.

May, K. (1982). Three phases of father involvement in pregnancy. Nursing Research, 31(6), 337-342.
Mezulis, A. H., Hyde, J. S., \& Clark, R. (2004). Father involvement moderates the effect of maternal depression during a child's infancy on child behavior problems in kindergarten. Journal of Family Psychology, 18(4), 575-588.

Ninio, A., \& Rinott, N. (1988). Father's involvement in the care of their infants and their attributions of cognitive competence to infants. Child Development, 59(3), 652-663.

Niström, K., \& Öhrling, K. (2004). Parenthood experiences during the child's first year: literature review. Journal of Advanced Nursing, 46(3), 319-330.

Parke, R. D. (1996). Fatherhood. Cambridge, Massachusetts: Harvard University Press.

Piccinini, C. A., Tudge, J., Lopes, R. S., \& Sperb, T. M. (1998). Estudo Longitudinal de Porto Alegre: Da Gestação à Escola. Porto Alegre: Instituto de Psicologia, UFRGS. Projeto de Pesquisa.

Piccinini, C. A., Silva, M. R, Gonçalves, T. R., Lopes, R. S., \& Tudge, J. (2004). O envolvimento paterno durante a gestação. Psicologia: Reflexão e Crítica, 17(3), 303-314.

Pleck, J. H. (1997). Paternal involvement: levels, sources, and consequences. In M. Lamb. (Ed.), The Role of the Father in Child Development (pp. 66-103). New York: John Wiley \& Sons.

Ramires, V. (1997). O exercício da paternidade. Rio de Janeiro: Ed. Rosa dos Ventos.

Rezende, A. L., \& Alonso, I. L. (1995). O perfil do pai cuidador. Revista Brasileira de Crescimento e Desenvolvimento Humano, $5(1 / 2), 66-81$.

Roggman, L. A. (2004). Do fathers just want to have fun? Commentary on theorizing the father-child relationship. Human Development, 47(4), 228-236.

Roggman, L., Boyce, L., Cook, G., \& Cook, J. (2003). Getting dads involved: Predictors of father involvement in early Head Start and with their children. Infant Mental Health Journal, 23(1-2), 62-78.

Rustia, J. G., \& Abott, D. (1993). Father involvement in infant care: two longitudinal studies. International Journal of Nursing Studies, 30(6), 467-47 6.

Sanderson, S., \& Thompson, V. T. (2002). Factors associated with perceived parental involvement in childbearing. Sex Roles, $46(3 / 4), 99-111$.

Silva, M. R. (2003). Sentimentos sobre a paternidade e envolvimento de pais que residem e pais que não residem com seus filhos. Dissertação de Mestrado, Universidade Federal do Rio Grande do Sul, Porto Alegre.

Silva, M. R., \& Piccinini, C. A. (2004). O envolvimento paterno em pais não-residentes: algumas questões teóricas. Psico, 35(2), 185-194.

Stern, D. N. (1997). A constelação da maternidade. Porto Alegre: Artes Médicas.

Tamis-Lemonda, C. (2004). Conceptualizing fathers' roles: Playmates and more. Human Development, 47(4), 220-227.

Trindade, Z. A., Andrade, C. A., \& Souza, Q. J. (1997). Papéis parentais e representações da paternidade: A perspectiva do pai. Psico, 28(1), 207-222.

Tudge, J., Doucet, E., Odero, D., Sperb, T., Piccinini., C., \& Lopes, R. (2006). A window into different cultural worlds: Young children's everyday activities in the United States, Kenya, and Brazil. Child Development, 77(5), 1446-1469. 
Winnicott, D. W. (1983). Teoria do relacionamento paterno-filial. In D. W. Winnicott. (Ed.), O Ambiente e os Processos de Maturação (pp. 38-54). Porto Alegre: Artmed (Original publicado em 1960).

Yeung, W. J., Sandberg, J. F., Davis-Kean, P. E.,. \& Hofferth, S. L. (2001). Children's time with fathers in intact families. Journal

\section{MUDANÇA DE ENDEREÇO}

Se você está mudando de endereço, por favor, notifique Psicologia: Teoria e Pesquisa. Ocasionalmente, assinantes e autores comunicam tardiamente mudança de endereço gerando dificuldades na entrega de nossa revista ou de outras correspondências. Informe imediatamente, se possível com antecedência, qualquer mudança de domicílio para:

Universidade de Brasília - Instituto de Psicologia

Revista Psicologia: Teoria e Pesquisa

Secretaria de Divulgação

70910-900 Brasília DF

Mudanças de endereço poderão também ser comunicadas através do correio eletrônico revptp@unb.br, telefone 5561 31076826 e fax 556131076892 . 